\title{
Switching the mode of sucrose utilization by Saccharomyces
} cerevisiae

\author{
Fernanda Badotti ${ }^{1}$, Marcelo G Dário수, Sergio L Alves Jr${ }^{1}$, Maria Luiza \\ A Cordioli ${ }^{1}$, Luiz C Miletti ${ }^{1,3}$, Pedro S de Araujo ${ }^{2}$ and Boris U Stambuk*1
}

\begin{abstract}
Address: ${ }^{1}$ Departamento de Bioquímica, Centro de Ciências Biológicas, Universidade Federal de Santa Catarina, Florianópolis, SC 88040-900, Brazil, ${ }^{2}$ Departamento de Bioquímica, Instituto de Química, Universidade de São Paulo, São Paulo, Brazil and ${ }^{3}$ Departamento de Produção Animal e Alimentos, Centro de Ciências Agroveterinárias, Universidade do Estado de Santa Catarina, Lages, Brazil

Email: Fernanda Badotti - fbadotti@yahoo.com.br; Marcelo G Dário - marcelogdario@hotmail.com; Sergio L Alves - slalvesjr@yahoo.com.br; Maria Luiza A Cordioli - luizacordioli@hotmail.com; Luiz C Miletti - lcmilett@yahoo.com.br; Pedro S de Araujo - psdarauj@usp.br; Boris U Stambuk* - bstambuk@mbox1.ufsc.br

* Corresponding author
\end{abstract}

Published: 27 February 2008

Microbial Cell Factories 2008, 7:4 doi:10.1 186/1475-2859-7-4
Received: 18 November 2007

Accepted: 27 February 2008

This article is available from: http://www.microbialcellfactories.com/content/7///4

(C) 2008 Badotti et al; licensee BioMed Central Ltd.

This is an Open Access article distributed under the terms of the Creative Commons Attribution License (http://creativecommons.org/licenses/by/2.0), which permits unrestricted use, distribution, and reproduction in any medium, provided the original work is properly cited.

\begin{abstract}
Background: Overflow metabolism is an undesirable characteristic of aerobic cultures of Saccharomyces cerevisiae during biomass-directed processes. It results from elevated sugar consumption rates that cause a high substrate conversion to ethanol and other bi-products, severely affecting cell physiology, bioprocess performance, and biomass yields. Fed-batch culture, where sucrose consumption rates are controlled by the external addition of sugar aiming at its low concentrations in the fermentor, is the classical bioprocessing alternative to prevent sugar fermentation by yeasts. However, fed-batch fermentations present drawbacks that could be overcome by simpler batch cultures at relatively high (e.g. $20 \mathrm{~g} / \mathrm{L}$ ) initial sugar concentrations. In this study, a $S$. cerevisiae strain lacking invertase activity was engineered to transport sucrose into the cells through a low-affinity and low-capacity sucrose- $\mathrm{H}^{+}$symport activity, and the growth kinetics and biomass yields on sucrose analyzed using simple batch cultures.

Results: We have deleted from the genome of a $S$. cerevisiae strain lacking invertase the highaffinity sucrose- $\mathrm{H}^{+}$symporter encoded by the $\mathrm{AGTI}$ gene. This strain could still grow efficiently on sucrose due to a low-affinity and low-capacity sucrose- $\mathrm{H}^{+}$symport activity mediated by the $M A L x I$ maltose permeases, and its further intracellular hydrolysis by cytoplasmic maltases. Although sucrose consumption by this engineered yeast strain was slower than with the parental yeast strain, the cells grew efficiently on sucrose due to an increased respiration of the carbon source. Consequently, this engineered yeast strain produced less ethanol and 1.5 to 2 times more biomass when cultivated in simple batch mode using $20 \mathrm{~g} / \mathrm{L}$ sucrose as the carbon source.

Conclusion: Higher cell densities during batch cultures on $20 \mathrm{~g} / \mathrm{L}$ sucrose were achieved by using a $S$. cerevisiae strain engineered in the sucrose uptake system. Such result was accomplished by effectively reducing sucrose uptake by the yeast cells, avoiding overflow metabolism, with the concomitant reduction in ethanol production. The use of this modified yeast strain in simpler batch culture mode can be a viable option to more complicated traditional sucrose-limited fed-batch cultures for biomass-directed processes of $S$. cerevisiae.
\end{abstract}




\section{Background}

The yeast Saccharomyces cerevisiae has been known to humans for thousands of years and it is routinely used in many traditional biotechnological processes, including bread making and production of several alcoholic beverages. Consequently, it has been extensively studied and thus is considered a model system for the metabolic, molecular and genetic analysis of eukaryotic organisms. Due to its GRAS status, S. cerevisiae yeasts are also applied on a huge scale in biomass-directed processes, such as the production of baker's yeast, yeast extract and other food additives (vitamins, proteins, enzymes, and flavouring agents) [1], as well as for production of heterologous proteins (including vaccines and other therapeutic compounds), or even for engineering completely novel metabolic pathways leading to the biotechnological production of important pharmaceuticals [2-5]. The combination of the large knowledge of yeast physiology, together with the fact that the yeast genome has been fully sequenced, has resulted in the development of production strains with optimized properties [6,7].

However, it should be stressed out that most of the industrial applications of $S$. cerevisiae rely in its ability to efficiently ferment sugars, even under fully aerobic conditions [8]. Since low by-product formation and a high biomass yield on sugar are prerequisites for the economic viability of biomass-directed applications, the occurrence of alcoholic fermentation in such processes is highly undesirable as it will reduce the biomass yield [9]. Aerobic ethanol production by $S$. cerevisiae cultures occurs when the carbon flux through glycolysis exceeds the capacity of the tricarboxylic acids cycle to completely oxidize the pyruvate produced. Thus, fully respiratory metabolism only takes place during the utilization of low sugar concentrations and slow rates of sugar consumption and growth, and plenitude of oxygen. Indeed, this yeast has developed several sensing and signaling mechanisms in order to not only ensure efficient sugar uptake from the medium, but to also repress alternative carbon source utilization and respiration, thus favoring the production of ethanol [10-14]. Accordingly, high cell concentrations are rarely feasible in a simple batch mode, as the required high initial sugar concentration would result in the significant production of ethanol, which can accumulate to values as high as $50 \%$ of the supplied sugar.

Consequently, in order to maximize biomass yield $S$. cerevisiae yeast cell are cultivated in a fed-batch manner, in which a sugar-concentrated solution is fed into the bioreactor under a variety of control strategies. Usually, after a batch phase, an exponential feeding profile is applied to ensure optimal production and growth conditions, followed by a decline phase at the end of cultivation. To ensure optimal oxidative growth several approaches have been developed to control the feed rate at a level below the critical value, beyond which ethanol is produced and therefore the biomass yield decreases. Nevertheless, supplementary equipment, complex control systems and kinetic models are usually required to monitor on-line the fermentation process in order to provide small sugar concentrations to the yeast cells, avoiding ethanol production [15-17]. Other technical and physical limitations, such as time delays or measurement noise, sub-optimal stirring and oxygen transfer, as well as non-homogenous supply of nutrients, may result in both a decrease of the growth rate of the microorganism and/or overflow metabolism, and consequently decreases in biomass productivity $[18,19]$. Many of these problems could be overcome by culturing the cells in the simpler batch mode, as long as overflow metabolism and/or ethanol production is prevented.

Sucrose is by far the most abundant, cheap and important sugar in the industrial utilization of the yeast $S$. cerevisiae. More than half of the world's ethanol production relies on the efficient fermentation of sucrose-rich broths such as sugarcane juice and molasses, and these raw materials are also used for the production of baker's yeast, and for production of several distilled alcoholic beverages [20,21]. It is generally accepted that $S$. cerevisiae cells harbor an extracellular invertase ( $\beta$-D-fructosidase), that hydrolyzes sucrose into glucose and fructose, which are transported into the cell by hexose transporters and metabolized through glycolysis. This enzyme has been a paradigm for the study of protein synthesis and regulation of gene expression. Invertase is encoded by one or several SUC genes (SUC1 to SUC5 and SUC7), SUC2 being the most common loci found in almost all $S$. cerevisiae strains, including in other closely related yeast species [22,23].

These SUC genes generate two different mRNAs: a larger transcript encoding an invertase with a signal sequence required for its secretion from the cell, and a shorter transcript lacking this signal sequence and thus coding for an intracellular form of the enzyme [24]. While the former mRNA is repressed by high concentrations of sucrose or its hydrolysis products (glucose and fructose), the intracellular invertase is expressed constitutively. Finally, it has recently become evident that efficient invertase expression requires low levels of glucose or fructose in the medium [25-27]. Despite significant improvements in our knowledge regarding the molecular mechanisms involved in the repression of SUC expression, the transcriptional activator of this gene is still unknown $[28,29]$. A further level of complexity is the fact that invertase levels at the yeast surface are poorly (or even inversely) correlated with the ability of the cells to ferment this sugar, especially at high sucrose concentrations [30-32]. Extracellular sucrose hydrolysis may even allow growth of other microorgan- 
isms, including contaminant yeasts lacking invertase [33]. Extracellular production of fructose also imposes several problems to the industrial process due to slower fructose utilization by $S$. cerevisiae cells [34], which may result in residual sugar at the end of the cultivation with consequent losses in productivity.

In this study, a poorly characterized pathway for sucrose utilization in S. cerevisiae was engineered in order to improve biomass-directed applications of this microorganism. Several reports have shown that the kinetics of cell growth on sucrose by this yeast can only fit a model in which its utilization is composed of the contributions from both the direct uptake of sucrose, and the uptake of its hydrolysis products into the cell [35-37]. The analysis of direct sucrose uptake by $S$. cerevisiae cells revealed the presence of an active sucrose- $\mathrm{H}^{+}$symport $[38,39]$ which was shown to be mediated by two different transport systems: high-affinity $\left(K_{\mathrm{m}} \sim 7 \mathrm{mM}\right)$ uptake mediated by the the AGT1 permease, while the MALx1 maltose transporters allow the active uptake of sucrose with low $\left(K_{\mathrm{m}}>100\right.$ $\mathrm{mM}$ ) affinity $[40,41]$. The active uptake of sucrose would justify the existence of the constitutive intracellular invertase, although sucrose can also be hydrolyzed by other intracellular glycosidases, such as $\alpha$-glucosidase (maltase), an enzyme with the same affinity and activity for sucrose and maltose [42]. Indeed, we have recently shown that yeast strains unable to ferment glucose or fructose due to the absence of hexose transport, or strains lacking invertase, can actively transport sucrose into the cells allowing efficient fermentation of this sugar $[43,44]$. In the present report we show that when we modulate at the molecular level the rate of active sucrose uptake, we obtain yeast strains that can easily attain higher cell densities when grown in simple batch cultures with $20 \mathrm{~g} / \mathrm{L}$ sucrose as carbon source. This novel and value strategy that improves one of the industrial applications of $S$. cerevisiae represents an interesting alternative to classical bioprocessing approaches.

\section{Results}

\section{Kinetics of active $\mathbf{H}^{+}$-sucrose uptake in yeast}

Strain $1403-7 A$ is a $M A L$ constitutive strain that lacks invertase activity, but it still grows and ferments efficiently sucrose due to its active transport into the cell, and intracellular hydrolysis by a cytoplasmic $\alpha$-glucosidase $[42,44,45]$. Since several different permeases (with differing kinetic properties) have been described as capable of active sucrose- $\mathrm{H}^{+}$symport [40], we decided to investigate the role that sugar transport could have on sucrose utilization by this yeast cells. Sucrose transport kinetics by strain 1403-7A (Figure 1) indeed indicated the presence of both a high-affinity $\left(K_{\mathrm{m}} \sim 7 \mathrm{mM}\right)$ and low-affinity $\left(K_{\mathrm{m}} \sim 120\right.$ $\mathrm{mM}$ ) transport activities, as has already been described for other wild-type yeast strains [40]. The AGT1 permease is responsible for the high-affinity component, while the low-affinity transport activity is mediated by any of the $M A L x 1$ maltose permeases. Indeed, this strain contains in its genome (Figure 2) at least 3 different MALx1 permeases, MAL21 (chromosome III), MAL31 (chromosome II), and MAL41 (chromosome XI), while the AGT1 gene is located in chromosome VII. It should be stressed out that both genetic and molecular studies [46,47] have already shown that in strain 1403-7A the MAL31, MAL41 and AGT1 permeases are functional, and we do not know if the MAL21 gene encodes for a functional permease. Our PFGE and blotting analysis also showed the presence of a unique SUC gene (SUC2 in chromosome IX, data not shown) in the genome of strain 1403-7A, probably a mutant $s u c 2$ allele of the gene since this strain lacks invertase activity $[42,44,45]$.

In order to develop a new yeast strain that would take up sucrose from the medium by just the low-affinity transport activity, we deleted from strain's 1403-7A genome the high-affinity sucrose- $\mathrm{H}^{+}$symporter encoded by the AGT1 gene (see strain LCM001 in Fig. 2). As expected, the kinetics of active sucrose transport indicated that in the

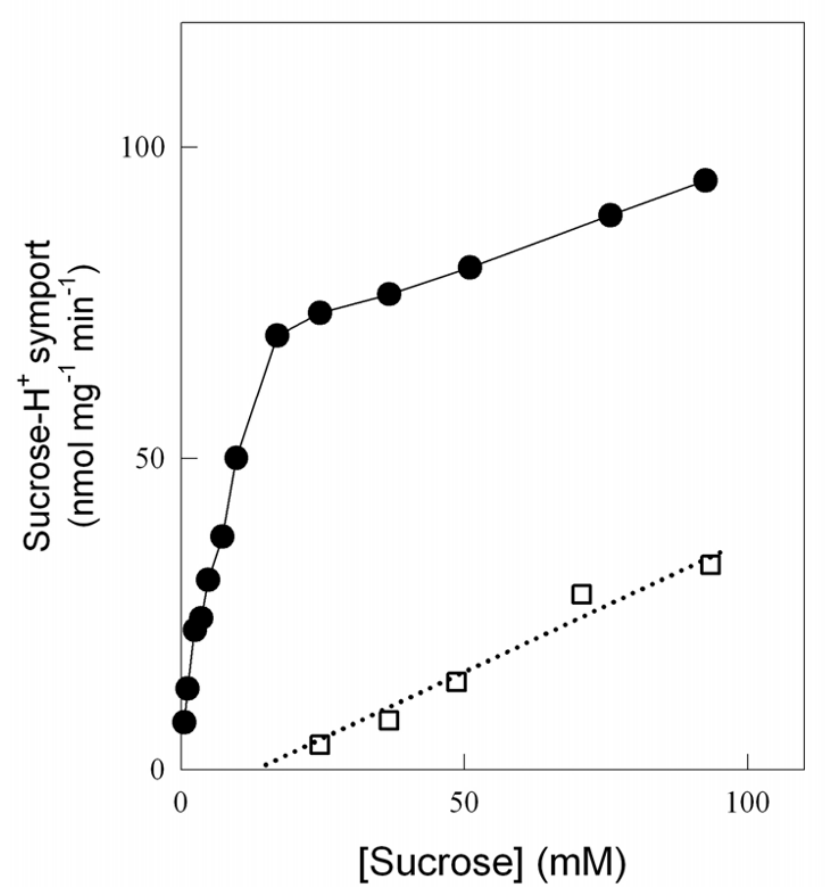

Figure I

Kinetics of active $\mathrm{H}^{+}$-sucrose symport activity in yeast strains. The initial rates of active $\mathrm{H}^{+}$co-transport with sucrose were determined in yeast cells from strain I403-7A (solid circles), or its agt I $\Delta$ counterpart strain LCM00 I (hollow squares), pre-grown in rich YP media containing $20 \mathrm{~g} / \mathrm{L}$ sucrose. 


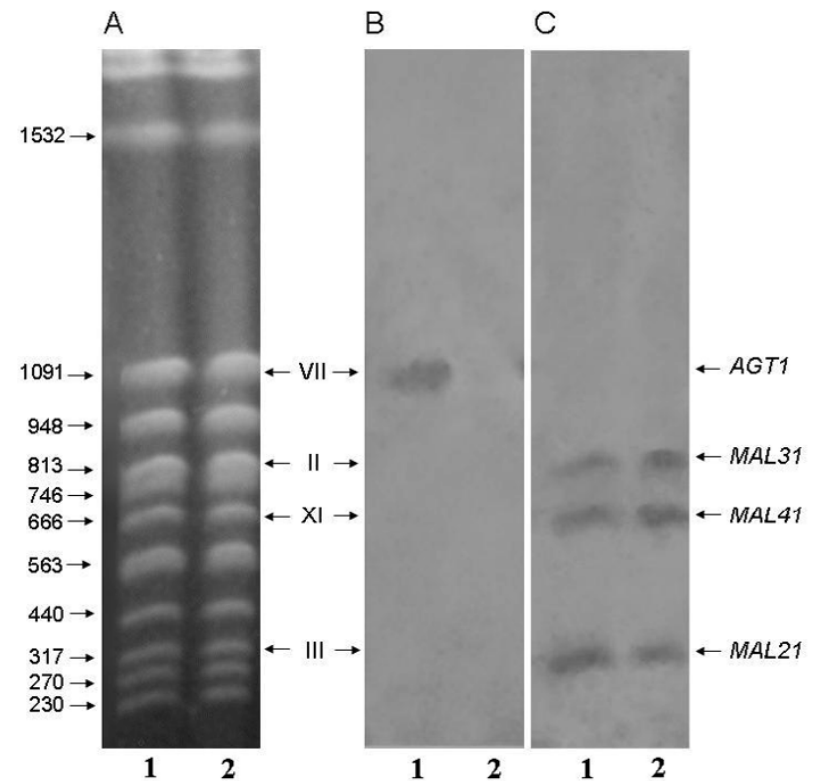

Figure 2

Detection of active sucrose transporter genes in yeast strains. Separation of chromosomes of yeast strains by PFGE and staining with ethidium bromide $(\mathbf{A})$, and detection of sucrose transporter genes after chromosomes were blotted onto a nylon membrane and hybridized with a probe for AGTI (B) or MALxI (C). Lanes I, strain I403-7A; lanes 2, the agt I $\Delta$ strain LCM00I. The values on the right in panel $A$ are the sizes (in kilobase pairs) of selected chromosomes, the Roman numerals between panels $A$ and $B$ are chromosome numbers, and the positions of chromosomes carrying $A G T I$, $M A L 2 I, M A L 3 /$ and MAL4I are indicated on the right of panel C. Both chromosome sizes and numbers, and locations of transporter genes, were based on results obtained with the reference strains S288C and MC966A (see Table I, data not shown).

agt1 $\Delta$ strain LCM001 sucrose- $\mathrm{H}^{+}$symport was mediated by a low-affinity and low-capacity transport activity (Fig. $1)$. Since the AGT1 permease is a low-affinity $\left(K_{\mathrm{m}} 20-30\right.$ $\mathrm{mM}$ ) maltose transporter [41], in strain LCM001 maltose uptake from the medium was normally mediated by the above indicated high-affinity MALx1 (MAL21, MAL31 and MAL41) maltose transport activities (data not shown).

\section{Sucrose utilization by yeast strains}

The kinetics of sucrose consumption and ethanol production during batch fermentations (Figure 3) indicated that the agt $1 \Delta$ strain LCM001 had a significant slower capacity to consume sucrose from the medium (at a concentration of $20 \mathrm{~g} / \mathrm{L}$ ), producing less ethanol than the parental wildtype strain 1403-7A. This phenotype was more pronounced when fermentations were performed in synthetic medium, compared with rich YP medium (Fig. 3). Strain
1403-7A showed rates of maximum sucrose consumption of 0.25 and $0.78 \mathrm{~g}$ sucrose ( $\mathrm{g}$ cell dry weight $)^{-1} \mathrm{~h}^{-1}$ in synthetic and rich medium, respectively, while the maximum sucrose consumption rate was reduced fourfold in the agt1 $\mathrm{LCM001}$ strain, to 0.06 and $0.17 \mathrm{~g}$ sucrose (g cell dry weight $)^{-1} \mathrm{~h}^{-1}$ in synthetic and rich medium, respectively. The beneficial effect of complex nitrogen sources (peptides or amino acids) compared with ammonium sulfate present in the synthetic medium has been described previously [48-50]. Furthermore, no major difference in the rates of sucrose consumption or ethanol production were observed among both strains when high sucrose concentrations (> $200 \mathrm{~g} / \mathrm{L}$ ) were used (Figure 4). The maximum sucrose consumption rates for the wildtype and the agt $1 \Delta$ strains were 0.99 and $0.78 \mathrm{~g}$ sucrose (g cell dry weight $)^{-1} \mathrm{~h}^{-1}$, respectively, which is in accordance with the kinetics of active sucrose transport presented by

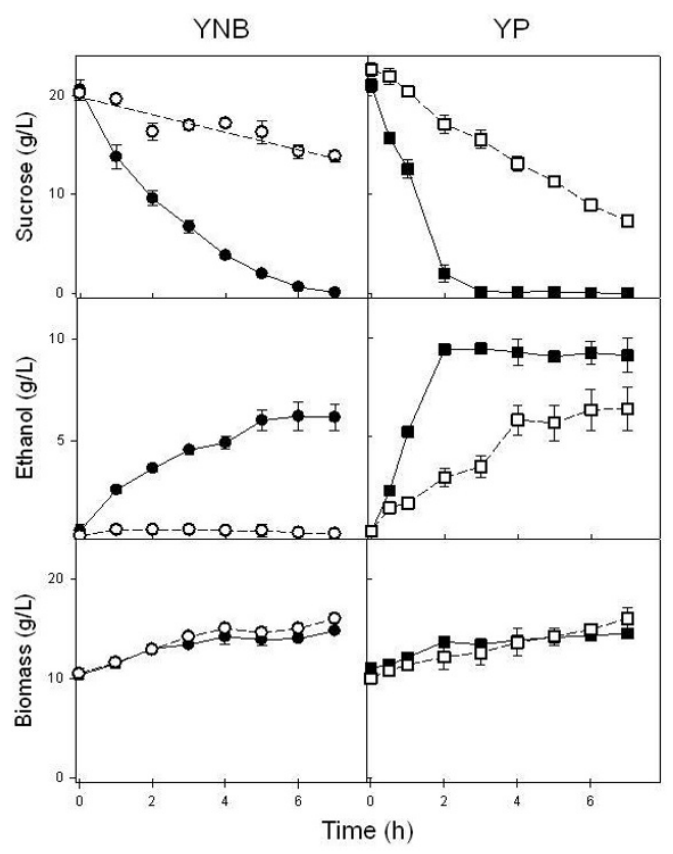

Figure 3

Batch fermentations of $\mathbf{2 0} \mathrm{g} / \mathrm{L}$ sucrose by yeast strains. The consumption of sucrose, and ethanol and biomass production during sucrose batch fermentations with 10 g/L yeast cells (dry weight) of strain I403-7A (black symbols) or strain LCMOOI (open symbols), were determined using synthetic YNB (circles) or rich YP (squares) medium. Data shown are means ( \pm range) from two independent experiments. 
each strain (Fig. 1). At $20 \mathrm{~g} / \mathrm{L}$ sucrose ( $58 \mathrm{mM}$ ) the low affinity transport system present in strain LCM001 is far from saturated (Fig. 1), while at this concentration the wild type strain's high-affinity transporter is operating with high capacity. At concentrations of $\sim 0.73 \mathrm{M}$ sucrose $(250 \mathrm{~g} / \mathrm{L})$, probably all transport activities present in both strains are operating with high capacity allowing efficient sucrose fermentation. An intriguing observation was that even when the yeast cells were consuming sucrose more slowly, the increases in biomass during these batch fermentations were the same for both strains (Fig. 3 and 4). This result indicated that strain LCM001 is preferring to respire more of the carbon source (sucrose), and not fermenting it into ethanol.

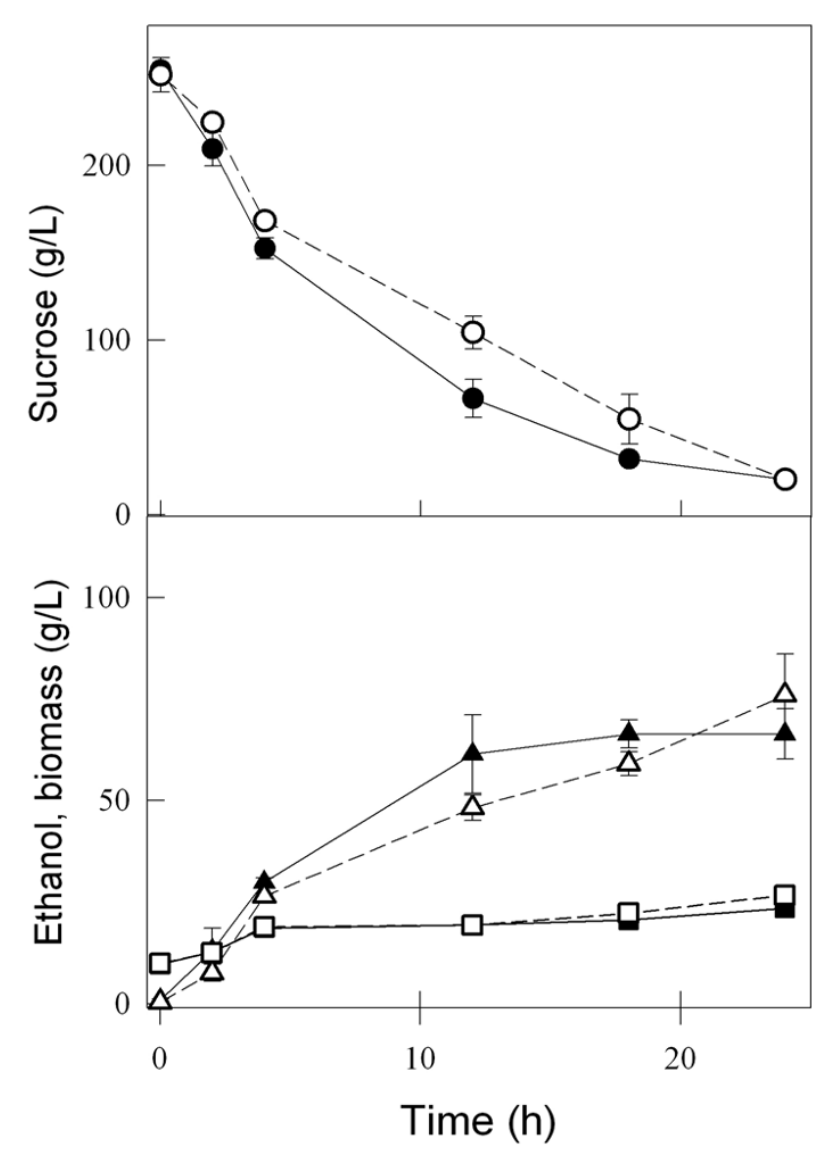

\section{Figure 4}

Batch fermentations of $\mathbf{2 5 0} \mathrm{g} / \mathrm{L}$ sucrose by yeast strains. The consumption of sucrose (circles), and ethanol (triangles) and biomass (squares) production during sucrose batch fermentations with $10 \mathrm{~g} / \mathrm{L}$ yeast cells (dry weight) of strain I403-7A (black symbols) or strain LCMOOI (open symbols) were determined with rich YP medium. Data shown are means ( \pm range) from two independent experiments.
Indeed, when we analyzed the kinetics of growth on sucrose by both strains (Figure 5), strain 1407-7A clearly presented a typical diauxic growth curve [51], where initially cell growth is coupled to efficient sugar consumption and ethanol production, when the carbon source is exhausted cells stop growing and the diauxic shift takes place, allowing the further consumption of the ethanol produced during sugar fermentation. However, strain LCM001 had a quite different pattern of sucrose utilization (Fig. 5). This agt1 $\Delta$ yeast grow on sucrose efficiently, with the same specific growth rate $\left(\mu=0.24 \pm 0.02 \mathrm{~h}^{-1}\right)$ as strain $1403-7 \mathrm{~A}\left(\mu=0.24 \pm 0.01 \mathrm{~h}^{-1}\right)$ or other $S U C^{+}$strains [44], although sugar consumption was slightly slower than with the wild-type strain $(0.26$ and $0.51 \mathrm{~g}$ sucrose $[\mathrm{g}$ cell dry weight ${ }^{-1} \mathrm{~h}^{-1}$ for strains LCM001 and 1403-7A, respectively). These LCM001 yeast cells did not enter into the diauxic shift (Fig. 5), but continued to grow efficiently through time, reaching higher cell densities than the parental strain 1403-7A. Although it is expected that these batch cultures become oxygen limited during exponential cell growth, favoring sugar fermentation, strain LCM001 not only produced less ethanol from sucrose, but also started to consume the ethanol produced during growth even when significant amounts of sugar ( $40 \%$ of initial value) still remained in the medium (Fig. 5). These results indicated that strain LCM001 had shifted its metabolism into a more aerobic sucrose utilization pattern than the parental strain.

We thus analyzed the biomass yield of these two strains during growth using three different carbon sources (glucose, maltose and sucrose) and different amounts (and quality) of nitrogen sources (Figure 6). It is evident that strain LCM001 produces from 1.5- to 2-fold more biomass during batch growth on sucrose (compared to the parental strain), while the biomass yields on glucose or maltose were unaffected. Conversely, while the ethanol yields on glucose by both the wild-type and the agt1 $\Delta$ strain were similar and varied from $Y_{\mathrm{e} / \mathrm{s}}$ values between $0.16 \pm 0.02$ and $0.31 \pm 0.03 \mathrm{~g}$ ethanol (g glucose) ${ }^{-1}$ when ammonium sulfate or peptone were used as nitrogen source, respectively, the agt $1 \Delta$ strain LCM001 produced only 10 to $40 \%$ of the ethanol produced by the wild-type strain 1403-7A when sucrose was used as carbon source. In order to confirm that this increase in biomass production by the LCM001 strain is due to respiration of the sugar, we added amtimycin A to the medium. Under this condition (respiration blocked), the biomass yield on sucrose of strain LCM001 was exactly the same as for the parental strain 1403-7A (Fig. 6), and both strains fermented sucrose efficiently $\left(Y_{\mathrm{e} / \mathrm{s}}=0.50 \pm 0.01 \mathrm{~g}\right.$ ethanol $[\mathrm{g}$ sucrose $]^{-1}$ ). 


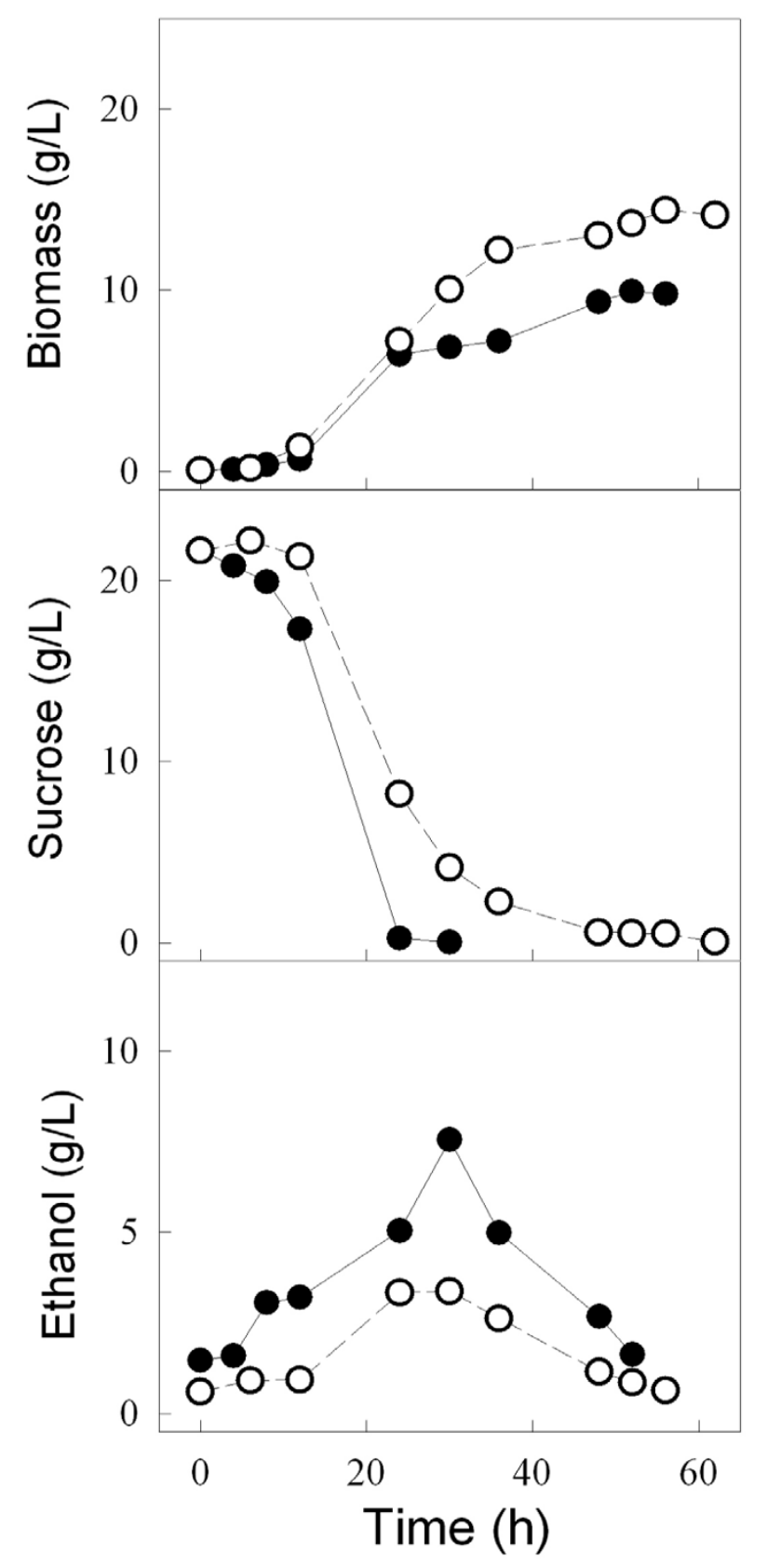

Figure 5

Batch growth of yeast strains on $\mathbf{2 0}$ g/L sucrose. The consumption of sucrose and the ethanol and biomass production by strain I403-7A (solid circles) or strain LCM00 I (hollow circles) were determined during growth in rich YP medium. For each strain a representative growth curve is shown.

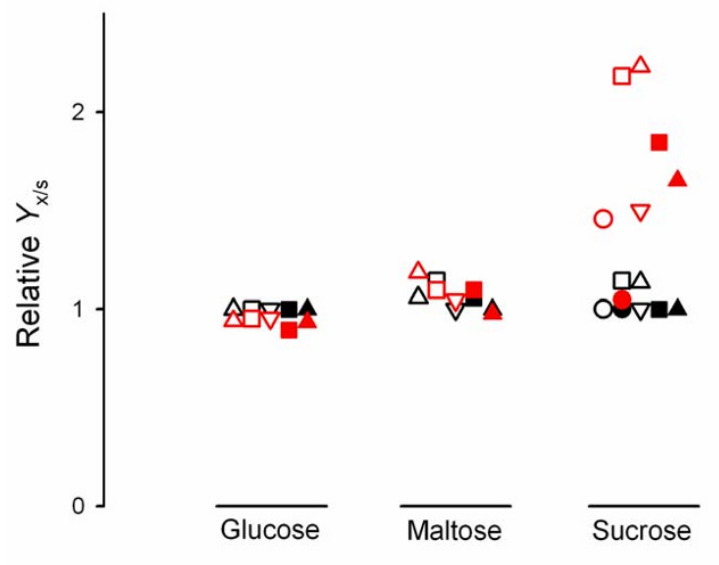

Figure 6

Biomass yields by yeast strains. The relative biomass yields, normalized to the values obtained by the wild-type I 403-7A strain in medium containing $20 \mathrm{~g} / \mathrm{L}$ glucose, were determined during growth of strain I403-7A (black symbols) or strain LCMOOI (red symbols) in synthetic yeast nitrogen medium containing 5 (triangles), 10 (squares) or I5 (inverted triangles) $\mathrm{g} / \mathrm{L}$ ammonium sulfate (open symbols) or peptone (close symbols) as nitrogen source, and $20 \mathrm{~g} / \mathrm{L}$ of the indicated carbon sources. Results obtained with rich YP medium (circles) in the absence (open symbols) or presence (close symbols) of antimycin $A$ are also shown. For the wild-type 1403-7A strain the $Y_{x / s}$ values varied between $0.20 \pm 0.02$ and $0.48 \pm 0.03 \mathrm{~g}$ biomass (g glucose) ${ }^{-1}$ when ammonium sulfate or peptone were used as nitrogen source, respectively, or $0.14 \mathrm{~g}$ biomass ( $\mathrm{g}$ sucrose $)^{-1}$ when antimycin $A$ was added to the medium.

\section{Discussion}

Due to the increased interest in biomass-based industrial applications of $S$. cerevisiae, several approaches have been developed to engineer the metabolism of this microorganism towards a more aerobic or respiratory utilization of sugars. In one approach where the targets are key regulatory proteins, either overexpression of the transcriptional factor HAP4 (activating respiratory genes), or deletion of GCR1 and GCR2 (activators of glycolytic genes), HXK2 or REG1 (relieving glucose repression), results in yeast strains showing increased biomass production during glucose fermentation [52-56]. However, modifying these regulatory circuits may also have some undesired side-effects, including significant reductions in the specific growth rate of the cells, and consequently losses in biomass productivity, or even altered patterns of sugar (other than glucose) utilization [57-61]. Another logic approach would be to restrict sugar uptake from the medium, which in the case of glucose transport by $S$. cer- 
evisiae was a huge challenge as it was required not only to delete the hole set of hexose transporters found in this yeast (compromising almost 20 different genes), but also required the expression of a mutant chimera between the low-affinity (HXT1) and high-affinity (HXT7) glucose transporters as the unique sugar permease at the plasma membrane [62-64]. Although this yeast strain will respire and produce higher biomass levels when grown on glucose, it still has some inconveniences, such as slow growth rates, fructose fermentation, and an inability to use other sugars (e.g. galactose, due to GAL2 deletion). Indeed, the modification of the glucose uptake system in $E$. coli $[65,66]$ also allowed the development of a bacteria with reduced overflow metabolism, and increased biomass production.

Our results show that when we engineer the mode of sucrose utilization by the yeast $S$. cerevisiae, allowing the direct uptake of the sugar by low-affinity and low-capacity transport systems, followed by its intracellular hydrolysis mediated by a maltase ( $\alpha$-glucosidase), the yeast cells grow efficiently on sucrose but produce significantly less ethanol since the cells are diverting more of this carbon source towards biomass production. Thus, higher biomass production can be attained with simple batch cultures in $20 \mathrm{~g} / \mathrm{L}$ sucrose, avoiding some drawbacks of fedbatch cultures due to easier operational procedures, reduced equipment and process time needed for each production lot. Indeed, the more respiratory phenotype of strain LCM001 was clearly demonstrated by the occurrence of only one growth phase during batch cultivation with sucrose as the carbon and energy source, and the corresponding decrease (to the same levels of the parental strain 1403-7A) in the biomass yield when the respiratory inhibitor antimycin A was used.

Although S. cerevisiae has a strong tendency towards alcoholic fermentation of sugars, several reports have shown that in the case of some $\alpha$-glucosides (e.g. maltotriose $[67,68]$ and trehalose [69-72]) which are transported by low-affinity and/or low-capacity uptake systems, the sugar may be completely respired by the yeast cell. However, these approaches have little practical application due to the high commercial prices of these sugar substrates. Nevertheless, all these studies, including the results shown in the present report, highlight the importance of the sugar transport step in the aerobic/fermentative dissimilation of sugars by yeast cells [73]. It is also important to emphasize that the engineering strategy utilized in the present approach does not affect the utilization (and fermentation) of other sugars (e.g. glucose, fructose, maltose) commonly used by yeasts, and thus would not affect the downstream utilization of such strains in important industrial applications such as bread making, or production of distilled beverages. The high specific growth rates observed during batch growth of the engineered strain on sucrose, even when the sugar is consumed more slowly, is probably a consequence of the superior efficiency of this sugar (when compared to glucose) for binding to and stimulate the GPR1 sugar receptor in S. cerevisiae cells, an important signaling system that controls, among several other physiological aspects, yeast cell growth [10,12]. It would thus be interesting to delete this GPR1 sugar receptor, and analyze the consequence of such deletion on the growth rate and metabolism of sucrose by $S$. cerevisiae cells. Finally, another way to further improve the biomass yield of yeasts grown at excess sucrose concentrations could be obtained by combining the properties of strain LCM001 with one or more of the above described strategies (e.g. HAP4 overexpression, and/or $h x k 2$ deletion), or even by using the classical fed-batch mode of yeast cultivation. It remains to be seen whether combination of such approaches can further improve the biomass yield of $S$. cerevisiae at higher sucrose concentrations.

\section{Conclusion}

Higher cell densities during batch cultures on sucrose were achieved by using a $S$. cerevisiae strain engineered in the sucrose transport system. Deletion of the high-affinity sucrose transport system mediated by the AGT1 permease produced a yeast strain where sucrose was transported by low-affinity and low-capacity permeases. While up to 1.5 to 2-times more biomass, when compared with the parental strain, were obtained by the engineered yeast strain in simple batch cultivations using $20 \mathrm{~g} / \mathrm{L}$ sucrose, the ability of the strains to efficiently ferment very-high sucrose concentrations (> $200 \mathrm{~g} / \mathrm{L}$ ) was unaffected. The yeast growth rate on rich medium containing $20 \mathrm{~g} / \mathrm{L}$ sucrose was also unaffected, and thus the higher biomass yields were accomplished by preventing overflow metabolism and increasing respiration by the engineered strain, with the concomitant reduction in ethanol production. The simpler batch cultivation mode can be a viable option to more complicated traditional sucrose-limited fed-batch cultures. A thorough analysis of the physiological and transcriptional response of the engineered $S$. cerevisiae strain to very-high sucrose concentrations will help to better understand the regulatory mechanisms involved in sugar fermentation by yeasts, and could serve as a basis for engineering metabolic pathways to improve process performance of $S$. cerevisiae for biomass directed approaches using highly concentrated culture media.

\section{Methods \\ Media and culture conditions}

Cells were routinely grown on rich YP medium $(10 \mathrm{~g} / \mathrm{L}$ yeast extract and $20 \mathrm{~g} / \mathrm{L}$ peptone), or synthetic medium (2 $\mathrm{g} / \mathrm{L}$ yeast nitrogen base without aminoacids containing 75 $\mathrm{mg} / \mathrm{L} \mathrm{L}$-tryptophane and $150 \mathrm{mg} / \mathrm{L}$ uracil) supplemented with different quantities of ammonium sulfate or peptone 
as nitrogen source, and $20 \mathrm{~g} / \mathrm{L}$ glucose, sucrose or maltose as carbon source. The $\mathrm{pH}$ of each medium was adjusted to $\mathrm{pH} 5.0$ with $\mathrm{HCl}$, and media was either sterilized by filtration (synthetic medium), or autoclaved at $120^{\circ} \mathrm{C}$ for 20 min (rich YP medium). When required, $20 \mathrm{~g} / \mathrm{L}$ agar, $3 \mathrm{mg} /$ $\mathrm{L}$ antimycin $\mathrm{A}$, or $200 \mathrm{mg} / \mathrm{L}$ geneticin (G-418) sulfate were added to the medium. Cells were grown aerobically at $28^{\circ} \mathrm{C}$ with shaking $(160 \mathrm{rpm})$ in cotton plugged Erlenmeyer flasks filled to $1 / 5$ of the volume with medium. The inoculum for growth assays was prepared by transferring aseptically a single colony from a plate into $5-10 \mathrm{~mL}$ of the selected medium containing $20 \mathrm{~g} / \mathrm{L}$ glucose, and allowed to growth into stationary phase for 2 to 3 days before they were used to inoculate (by a $100 \times$ dilution) new media containing the indicated carbon sources. Culture samples were harvested regularly, centrifuged $(5,000$ $g, 1 \mathrm{~min}$ ), and their supernatants used for the determination of sugars and ethanol. For batch fermentations yeasts were pregrown on YP- $20 \mathrm{~g} / \mathrm{L}$ sucrose until the exponential phase ( $\sim 1 \mathrm{~g}$ of dry yeast/L), centrifuged $(3,500 \mathrm{~g}, 3 \mathrm{~min})$ and washed twice with cold water, and inoculated at a high cell density (10 g of dry yeast/L) into synthetic medium ( $4 \mathrm{~g} / \mathrm{L}$ yeast nitrogen base without aminoacids and $10 \mathrm{~g} / \mathrm{L}$ ammonium sulfate) or rich YP medium containing the indicated amounts of sucrose. Batch fermentations were incubated as described above for growth assays, and samples were collected regularly, centrifuged, and their supernatants analyzed as described below.

\section{Yeast strains}

The S. cerevisiae strains and oligonucleotides used in the present study are described in Table 1 . The yeast strains were kept at $-80^{\circ} \mathrm{C}$ in $25 \%$ sterile glycerol, and from these frozen stocks yeast cells were streaked onto solid YP-2\% glucose plates, incubated for 2 days at $28^{\circ} \mathrm{C}$, and stored at $4^{\circ} \mathrm{C}$ (for a maximum of 1 month) until use. Standard methods for yeast transformation, DNA manipulation and analysis were employed [74]. The AGT1 gene was deleted according to the polymerase chain reaction (PCR)-based gene replacement procedure as described previously $[43,50]$. Briefly, the kanMX cassette from plasmid pFA6a-kanMX6 [75] was amplify with primers AGT1pFA6-F1 and AGT1-pFA6-R1, and the resulting PCR product of 1,579-bp was used to transform competent yeast cells. After 2-hour cultivation on YP-20 g/L glucose, the transformed cells were plated on the same medium containing G-418 and incubated at $28^{\circ} \mathrm{C}$. G-418-resistant isolates were tested for proper genomic integration of the kanMX cassette at the AGT1 locus by Southern analysis (see below) and analytical colony PCR using 3 primers (VAGT1-F, V-AGT1-R and V-kanr-R; Table 1). These set of 3 primers amplified a 1,938-bp fragment from a normal AGT1 locus, or yielded an 813-bp fragment if the kanMX cassette was correctly integrated at this locus and replaced the AGT1 gene.

\section{PFGE, chromosome blotting and hybridization}

Yeast chromosomes were prepared as previously described [76] from $1 \mathrm{ml}$ of yeast cells pre-grown in YP$2 \%$ glucose medium and collected at the stationary phase of growth. Cells were washed with $10 \mathrm{mM}$ Tris-HCl, $\mathrm{pH}$ 7.5, containing $50 \mathrm{mM}$ EDTA, and resuspended in the 0.4 $\mathrm{ml}$ of $4 \mathrm{mM}$ Tris- $\mathrm{HCl}, \mathrm{pH}$ 7.5, containing $95 \mathrm{mM}$ EDTA, $130 \mathrm{mg} / \mathrm{L}$ of Zymolyase $20 \mathrm{~T}$ and $7 \mathrm{~g} / \mathrm{L}$ of molten $\left(42^{\circ} \mathrm{C}\right)$ low-melting-point agarose. After solidification in a mold (Pharmacia Biotech), the agarose blocks were immersed

Table I: Saccharomyces cerevisiae strains and oligonucleotides used in this study

\begin{tabular}{|c|c|c|}
\hline & Relevant genotype or description: & Source or reference: \\
\hline \multicolumn{3}{|l|}{ Yeast Strains } \\
\hline I403-7A & MATa MAL4CMGL3 sucgal3 gal4 trpl ura3 & ATTC 208023 \\
\hline LCM00I & agt I $\triangle:: k a n M X 6$ derivative of I403-7A & This study \\
\hline S288C & MAT $\alpha A G T I$ MALI 2 mall3 MAL3I MAL32 mal33 gal2 mel flol flo8-I hap I SUC2 & $(39)$ \\
\hline MC966A & MATa MAL2 ura3-52 his3-II, I5 leu2-3, II 2 SUC2 & $(43)$ \\
\hline \multicolumn{3}{|c|}{ 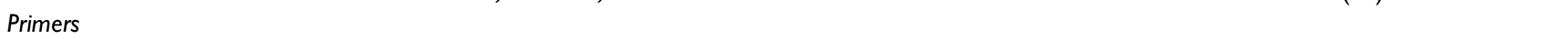 } \\
\hline AGTI-pFA6-FI & $\begin{array}{l}\text { AAGCAAGAAGAAGGCTGCCTCAAAAAATGAGGATAAAAACATTTCTGAGCGGATCCCCGGGT } \\
\text { TAATTAA }\end{array}$ & Invitrogen \\
\hline AGTI-pFA6-RI & $\begin{array}{l}\text { AAAGGGATTCCTTATTTCTTCCAAAAAAAAAAAAACAACCCTTTTACTTAGAATTCGAGCTCGT } \\
\text { TTAAAC }\end{array}$ & $"$ \\
\hline AGTI-F & AGGAGCTCATGAAAAATATCATTTCATTGG & Gibco BRL \\
\hline AGTI-R & TTGGATCCACATTTATCAGCT GC & " \\
\hline MALXI-F & CCATACTTGTTGTGAGTGG & $"$ \\
\hline MALxI-R & TCATTTGTTCACAACAGATG & Invitrogen \\
\hline SUC2-F & GCGATAGACCTTTGGTCCAC & Gibco BRL \\
\hline SUC2-R & GGACCGTGGTAACTCTAAGG & $"$ \\
\hline V-AGTI-F & GAATTTTCGGGTTGGTG & $"$ \\
\hline V-AGTI-R & TTGGATCCACATTTATCAGCTGC & $"$ \\
\hline V-kanr-R & GGAATCGAATGCAACCGG & $"$ \\
\hline
\end{tabular}


in $10 \mathrm{mM}$ Tris- $\mathrm{HCl}, \mathrm{pH} 7.5$, containing $0.5 \mathrm{M}$ EDTA, and incubated at $37^{\circ} \mathrm{C}$ for 8 hours. Following a subsequent incubation in $10 \mathrm{mM}$ Tris- $\mathrm{HCl}, \mathrm{pH} 9.5$, containing $0.5 \mathrm{M}$ EDTA, $1 \% \mathrm{~N}$-lauroylsarcosine, and $2 \mathrm{~g} / \mathrm{L}$ proteinase $\mathrm{K}$ at $50^{\circ} \mathrm{C}$ overnight, the blocks were washed in $10 \mathrm{mM}$ Tris$\mathrm{HCl}, \mathrm{pH} 7.5$, containing $50 \mathrm{mM}$ EDTA, and stored at $4{ }^{\circ} \mathrm{C}$ in the same buffer. Each low-melting-point agarose block was transferred to a $10 \mathrm{~g} / \mathrm{L}$ agarose gel in $50 \mathrm{mM}$ Tris- $\mathrm{HCl}$, pH 8.3, containing $50 \mathrm{mM}$ boric acid and $1 \mathrm{mM}$ EDTA. Pulsed field gel electrophoresis (PFGE) was performed at $10^{\circ} \mathrm{C}$ using a Gene Navigator pulsed-field system (Pharmacia Biotech) for a total of 27 hours at $200 \mathrm{~V}$. The pulse time was stepped from 70 seconds after 15 hours to 120 seconds for 12 hours. Following electrophoresis, the gel was stained with ethidium bromide and photographed. The chromosomes separated by PFGE were transferred to a nylon filter (Biodyne A, Gibco BRL) by capillary blotting [74], and labeling of DNA probes (see below), including the pre-hybridization, hybridization, stringency washes and chemiluminescent signal generation and detection was performed by using a AlkPhos kit (GE Healthcare/ Amersham Biosciences) as recommended by the manufacturer. After hybridization, an autoradiography film (Hiperfilm $^{\mathrm{TM}}$ ECL - Kodak) was exposed to the membrane for 2 to $3 \mathrm{~h}$ before it was developed. Images were obtained by scanning with an ImageScanner ${ }^{\mathrm{Tm}}$ (Amersham Biosciences) and annotated with Microsoft PowerPoint. Probes corresponding to nucleotides +1 through +1848 on the AGT1 ORF, -73 through +1845 of the MAL31 gene, or +77 through +1333 of the SUC2 locus were generated by PCR using primers AGT1-F and AGT1-R, MAL31-F and MAL31-R, and SUC2-F and SUC2-R (Table 1), respectively.

\section{Analytical methods}

Sucrose was quantified using $50 \mathrm{U} / \mathrm{mL}$ of yeast $\beta$-D-fructosidase (Sigma) in $50 \mathrm{mM}$ citrate-phosphate buffer, $\mathrm{pH}$ 4.5, followed by glucose determination. Glucose was measured by the glucose oxidase and peroxidase method using a commercial kit (BioDiagnostica-Laborclin). Maltose was determined spectrophotometrically at $540 \mathrm{~nm}$ with methylamine in $0.25 \mathrm{M} \mathrm{NaOH}$ as described previously [50]. Ethanol was determined with alcohol oxidase and peroxidase as described previously [44,50]. Cellular growth was followed by turbidity measurements at 570 $\mathrm{nm}$ after appropriate dilution, and yeast cell dry weight was determined as described elsewhere [77]. Briefly, from 1 to $5 \mathrm{~mL}$ of fermentation broth was filtered through preweighed filters $(0.45 \mu \mathrm{m}$ mixed nitrocellulose and cellulose acetate filters), washed twice with $5 \mathrm{~mL}$ of distilled water, and after placing in a small ( $5 \mathrm{~cm}$ diameter) covered Petri dish, dried for 3 to $5 \mathrm{~min}$ in a microwave oven at maximum power $(900 \mathrm{~W})$ until constant weight. The sugar consumption rates were calculated using samples harvested from the logarithmic growth phase and/or in intervals during which maximal rates were attained. Mean values of dry weight in the specified time intervals were used in the rate calculations. Specific growth rate $\left(\mu, h^{-1}\right)$ was determined as slope of a straight line between ln $\mathrm{OD}_{570 \mathrm{~nm}}$ and time $(\mathrm{h})$ during the initial ( $\left.12 \mathrm{~h}\right)$ exponential phase of growth. Biomass and ethanol yield coefficients $\left(Y_{\mathrm{x} / \mathrm{s}}\right.$ and $Y_{\mathrm{e} / \mathrm{s}}$, respectively) were obtained at the end of cell growth or ethanol production, taking into account the amount of sugar utilized. The kinetics of active $\mathrm{H}^{+}-$ sucrose or $\mathrm{H}^{+}$-maltose symport were determined as previously described $[40,41]$ using a PHM84 research pH meter attached to a TT1 Servograph (Radiometer, Copenhagen). Initial rates of sugar-induced proton uptake were calculated from the slope of the initial part $(<10 \mathrm{~s})$ of the curve obtained in the recorder, subtracting the basal rate of proton uptake observed before addition of $0.1-100 \mathrm{mM}$ of the sugar. All determinations were done at least in duplicate, and assays were monitored so that no more than $5 \%$ of the substrate was depleted. All activities were expressed as nmol of substrate transported per mg dry cell weight per min.

\section{Competing interests}

The author(s) declare that they have no competing interests.

\section{Authors' contributions}

FB, MGD, SLA-J, MLAC, LCM and BUS conceived, designed and performed the experiments. PSDA and BUS contributed with reagents and materials, analyzed the data, and wrote the paper. All authors read and approved the final version of the manuscript.

\section{Acknowledgements}

This work was supported in part by grants from the Brazilian agencies CNPq ( ${ }^{\circ}$ 502999/2004-7) and FAPESP ( $\left.N^{\circ} 04 / 10067-6\right)$. All authors were recipients of scholarships or research fellowships from CNPq or CAPESBrazil. We thank M. Longtine (University of North Carolina) and A. Kruckeberg (University of Amsterdam) for providing plasmid pFA6a-kanMX6 and yeast strains, respectively.

\section{References}

I. Bekatorou A, Psarianos C, Koutinas AA: Production of food grade yeasts. Food Technol Biotechnol 2006, 44:407-4I 5.

2. Hensing MC, Rouwenhorst RJ, Heijnen JJ, van Dijken JP, Pronk JT: Physiological and technological aspects of large-scale heterologous-protein production with yeasts. Antonie van Leeuw 1995, 67:26I-279.

3. Chemler JA, Yan Y, Koffas MA: Biosynthesis of isoprenoids, polyunsaturated fatty acids and flavonoids in Saccharomyces cerevisiae. Microb Cell Fact 2006, 23:20.

4. Ro DK, Paradise EM, Ouellet M, Fisher KJ, Newman KL, Ndungu JM, Ho KA, Eachus RA, Ham TS, Kirby J, Chang MCY, Withers ST, Shiba $Y$, Sarpong R, Keasling JD: Production of the antimalarial drug precursor artemisinic acid in engineered yeast. Nature 2006, 440:940-943.

5. Galao RP, Scheller N, Alves-Rodrigues I, Breinig T, Meyerhans A, Díez $\mathrm{J}$ : Saccharomyces cerevisiae : a versatile eukaryotic system in virology. Microb Cell Fact 2007, 6:32.

6. Sagt CM, Kleizen B, Verwaal R, de Jong MD, Muller WH, Smits A, Visser C, Boonstra J, Verkleij AJ, Verrips CT: Introduction of an N- 
glycosylation site increases secretion of heterologous proteins in yeasts. Appl Environ Microbiol 2000, 66:4940-4944.

7. Sleep D, Finni C, Evans L: Enhanced protein expression through strain selection, gene disruption, improved vector design and co-expression of endogenous chaperones. Microb Cell Fact 2006, 5:S29.

8. Lagunas R: Energetic irrelevance of aerobiosis for S. cerevisiae growing on sugars. Mol Cel Biochem 1979, 27: I39-146.

9. Verduyn C, Stouthamer AH, Scheffers WA, van Dijken JP: A theoretical evaluation of growth yields of yeasts. Antonie van Leeuw I991, 59:49-63.

10. Rolland F, Winderickx J, Thevelein JM: Glucose-sensing and -signaling mechanisms in yeasts. FEMS Yeasts Res 2002, 2:183-20|.

II. Bisson LF, Kunathigan V: On the trail of an elusive flux sensor. Res Microbiol 2003, 154:603-610.

12. Lemaire K, Van de Velde S, Van Dijck P, Thevelein JM: Glucose and sucrose act as agonist and mannose as antagonist ligands of the G protein-coupled receptor Gprl in the yeast Saccharomyces cerevisiae. Mol Cell 2004, 16:293-299.

13. Moreno F, Ahuatzi D, Riera A, Palomino CA, Herrero P: Glucose sensing through the Hxk2-dependent signalling pathway. Biochem Soc Trans 2005, 33:265-268.

14. Frick O, Wittmann C: Characterization of the metabolic shift between oxidative and fermentative growth in Saccharomyces cerevisiae by comparative ${ }^{13} \mathrm{C}$ flux analysis. Microb Cell Fact 2005, 4:30.

15. Hisbollah MAH, Ramachandran KB: Comparative evaluation of various control schemes for fed-batch fermentation. Bioprocess Eng 2002, 24:309-3I8.

16. Cannizzaro C, Valentinotti S, von Stockar U: Control of yeast fedbatch process through regulation of extracellular ethanol concentration. Bioprocess Biosyst Eng 2004, 26:377-383.

17. Finn B, Harvey LM, McNeil B: Near-infrared spectroscopic monitoring of biomass, glucose, ethanol and protein content in a high cell density baker's yeast fed-batch bioprocess. Yeast 2006, 23:507-517.

18. Riesenberg D, Guthke R: High-cell-density cultivation of microorganisms. Appl Microbiol Biotechnol I 999, 5 I:422-430.

19. Enfors SO, Jahic $M$, Rozkov $A, X u B$, Hecker $M$, Jürgen $B$, Krüger $E$, Schweder T, Hamer G, O'Beirne D, Noisommit-Rizzi N, Reuss M, Boone L, Hewitt C, McFarlane C, Nienow A, Kovacs T, Trägardh C, Fuchs L, Revstedt J, Friberg PC, Hjertager B, Blomsten G, Skogman H, Hjort S, Hoeks F, Lin HY, Neubauer P, van der Lans R, Luyben K, Vrabel $P$, Manelius A: Physiological responses to mixing in large scale bioreactors. J Biotechnol 200I, 85: 175- I85.

20. Berg C: World fuel ethanol - analysis and outlook. [http:// www.distill.com/World-Fuel-Ethanol-A\&O-2004.html].

21. Peters D: Carbohydrates for fermentation. Biotechnol ] 2006, $\mathrm{I}: 806-8 \mid 4$

22. Naumov GI, Naumova ES, Sancho ED, Korhola MP: Polymeric SUC genes in natural populations of Saccharomyces cerevisiae. FEMS Microbiol Lett 1996, 135:3 I-35.

23. Korshunova IV, Naumova ES, Naumov GI: Comparative molecular genetic analysis of $\beta$-fructosidases of yeasts Saccharomyces. Mol Biol 2005, 39:413-4I9.

24. Carlson $M$, Botstein $D$ : Two differentially regulated mRNAs with different 5' $^{\prime}$ ends encode secreted and intracellular forms of yeast invertase. Cell 1982, 28: | 45- I54.

25. Bokossa IP, Krastanov Al, Rochkova Z, Angelov A: Biosynthesis of invertase by Saccharomyces cerevisiae with sugarcane molasses as substrate. World J Microbio Biotech 1993, 9:662-663.

26. Ozcan S, Vallier LG, Flick JS, Carlson M, Johnston M: Expression of the SUC2 gene of Saccharomyces cerevisiae is induced by low levels of glucose. Yeast 1997, 13:127-137.

27. Herwing C, Doerries C, Marison I, von Stockar U: Quantitative analysis of the regulation scheme of invertase expression in Saccharomyces cerevisiae. Biotechnol Bioeng 200I, 76:247-258.

28. Belinchón MM, Gancedo JM: Different signalling pathways mediate glucose induction of SUC2, HXTI and pyruvate decarboxylase in yeast. FEMS Yeast Research 2007, 7:40-47.

29. Belinchón MM, Gancedo JM: Glucose controls multiple processes in Saccharomyces cerevisiae through diverse combinations of signaling pathways. FEMS Yeast Research 2007, 7:808-818

30. Takeshige K, Ouchi K: Effects of yeast invertase on ethanol production in molasses. J Ferment Bioeng 1995, 79:513-515.
31. Myers DK, Lawlor DTM, Attfield PV: Influence of invertase activity and glycerol synthesis and retention on fermentation of media with a high sugar concentration by Saccharomyces cerevisiae. Appl Environ Microbiol 1997, 63:145-I50.

32. Echegaray OF, Carvalho JCM, Fernandes ANR, Sato S, Aquarone E, Vitolo M: Fed-batch culture of Saccharomyces cerevisiae in sugar-cane blackstrap molasses: invertase activity of intact cells in ethanol fermentation. Biomass Bioenergy 2000, 19:39-50.

33. Greig D, Travisano M: The Prisoner's Dilemma and polymorphism in yeast SUC genes. Proc Biol Sci 2004, 27 I:S25-S26.

34. Berthels NJ, Otero RRC, Bauer FF, Thevelein JM, Pretorius IS: Discrepancy in glucose and fructose utilization during fermentation by Saccharomyces cerevisiae wine yeast. FEMS Yeast Res 2004, 4:683-689.

35. Orlowski JH, Barford JP: Direct uptake of sucrose by Saccharomyces cerevisiae in batch and continuous culture. J Gen Appl Microbiol 1991, 37:215-218.

36. Barford JP, Phillips PJ, Orlowski JH: A new model of uptake of multiple sugars by S. cerevisiae. Bioproc Eng 1992, 7:303-307.

37. Mwesigye PK, Barford JP: Mechanism of sucrose utilization by Saccharomyces cerevisiae. J Gen Appl Microbiol 1996, 42:209-306.

38. Mwesigye PK, Barford JP: Transport of sucrose by Saccharomyces cerevisiae. J Ferment Bioeng 1994, 77:687-690.

39. Stambuk BU, da Silva MA, Panek AD, de Araújo PS: Active $\alpha$-glucoside transport in Saccharomyces cerevisiae. FEMS Microbiol Letters 1999, 170:105-110

40. Stambuk BU, Batista AS, de Araújo PS: Kinetics of active sucrose transport by Saccharomyces cerevisiae. J Biosci Bioeng 2000, 89:2|2-2|4

4I. Stambuk BU, de Araújo PS: Kinetics of active $\alpha$-glucoside transport by Saccharomyces cerevisiae. FEMS Yeast Res 200I, I:73-78.

42. Khan NA, Zimmermann FK, Eaton NR: Genetic and biochemical evidence of sucrose fermentation by maltase in yeast. $J \mathrm{Mol}$ Gen Genet 1973, I 23:43-50.

43. Batista AS, Miletti LC, Stambuk BU: Sucrose fermentation by Saccharomyces cerevisiae lacking hexose transport. J Mol Microbiol Biotechnol 2004, 8:26-33.

44. Badotti F, Batista AS, Stambuk BU: Sucrose active transport and fermentation by Saccharomyces cerevisiae. Braz Arch Biol Technol 2006, 49:s||5-s| 23.

45. Oda Y, Ouchi K: Construction of a sucrose-fermenting baker's yeast incapable of hydrolysing fructooligosaccharides. Enzyme Microb Technol 199I, 13:495-498.

46. Han EK, Cotty F, Sottas C, Jiang H, Michels CA: Characterization of AGTI encoding a general $\alpha$-glucoside transporter from Saccharomyces. Mol Microbiol 1995, I7:1093-1107.

47. Michels CA, Needleman RB: The dispersed, repeated family of MAL loci in Saccharomyces spp. J Bacteriol 1984, I 57:949-952.

48. Da Cruz SH, Cilli EM, Ernandes JR: Structural complexity of the nitrogen source and influence on yeast growth and fermentation. J Inst Brew 2002, I 08:54-6I.

49. Shimizu H, Mizuno S, Hiroshima T, Shioya S: Effect of carbon and nitrogen additions on consumption activity of apparent extract of yeast cells in a brewing process. J Am Soc Brew Chem 2002, 60:163-169.

50. Alves SL Jr, Herberts RA, Hollatz C, Miletti LC, Stambuk BU: Maltose and maltotriose active transport and fermentation by Saccharomyces cerevisiae. J Am Soc Brew Chem 2007, 65:99-104.

5I. Lewis JG, Northcott C], Learmonth RP, Attfield PV, Watson K: The need for consistent nomenclature and assessment of growth phases in diauxic cultures of Saccharomyces cerevisiae. J Gen Microbiol 1993, 139:835-839.

52. Blom I, De Matos JMT, Grivell LA: Redirection of the respirofermentative distribution in Saccharomyces cerevisiae by overexpression of the transcription factor Hap4p. Appl Environ Microbiol 2000, 66: 1970-1973.

53. Van Maris AJA, Bakker BM, Brandt M, Boorsma A, De Mattos MJT, Grivell LA, Pronk JT, Blom J: Modulating the distribution of fluxes among respiration and fermentation by overexpression of HAP4 in Saccharomyces cerevisiae. FEMS Yeast Res 200I, I:I39-149.

54. Diderich JA, Raamsdonk LM, Kruckeberg AL, Berden JA, van Dam K: Physiological properties of Saccharomyces cerevisiae from which hexokinase II has been deleted. Appl Environ Microbiol 200I, 67:1587-1593. 
55. Diderich JA, Raamsdonk LM, Kuiper A, Kruckeberg AL, Berden JA, de Mattos MJT, van Dam K: Effects of a hexokinase II deletion on the dynamics of glycolysis in continuous cultures of Saccharomyces cerevisiae. FEMS Yeast Res 2002, I 482: I-8.

56. Sasaki $\mathrm{H}$, Uemura $\mathrm{H}$ : Influence of low glycolytic activities in gcr I and gcr 2 mutants on the expression of other metabolic pathway genes in Saccharomyces cerevisiae. Yeast 2005, 22: I | |-27.

57. Entian KD, Loureiro-Dias MC: Misregulation of maltose uptake in a glucose repression defective mutant of Saccharomyces cerevisiae leads to glucose poisoning. J Gen Microbiol 1990, I36:855-860.

58. Lascaris R, Bussemaker HJ, Boorsma A, Piper M, van der Spek H, Grivell L, Blom J: Hap4p overexpression in glucose-grown Saccharomyces cerevisiae induces cells to enter a novel metabolic state. Genome Biol 2002, 4:I-I0.

59. Lascari R, Piwowarski J, Van der Spek H, de Mattos JT, Grivell L, Blom ]: Overexpression of HAP4 in glucose-derepressed yeast cells reveals respiratory control of glucose-regulated genes. Microbiology 2004, I 50:929-934.

60. Herwig C, Chetreanu F, Niederberger P, Marison I, Stockar UV: Quantitative analysis of the impact of HXK2 and REGI deletion in Saccharomyces cerevisiae on invertase expression and respiration. Enzyme Microbial Technol 2002, 31:505-5I 5.

6I. Barbara KE, Haley TM, Willis KA, Santangelo GM: The transcription factor Gcrl stimulates cell growth by participating in nutrient-responsive gene expression on a global level. $\mathrm{Mol}$ Genet Genomics 2007, 277:171-88.

62. Otterstedt K, Larsson C, Bill RM, Stahlberg A, Boles E, Hohmann S, Gustafsson L: Switching the mode of metabolism in the yeast Saccharomyces cerevisiae. EMBO Rep 2004, 5:532-537.

63. Elbing K, Larsson C, Bill RM, Albers E, Snoep JL, Boles E, Hohmann S, Gustafsson L: Role of hexose transport in control of glicolytic flux in Saccharomyces cerevisiae. Appl Environ Microbiol 2004, 70:5323-5330.

64. Henricsson C, de Jesus Ferreira MC, Hedfalk K, Elbing K, Larsson C, Bill RM, Norbeck J, Hohmann S, Gustafsson L: Engineering of a novel Saccharomyces cerevisiae wine strain with a respiratory phenotype at high external glucose concentrations. Appl Envir Microbiol 2005, 71:6185-6192.

65. Gosset G: Improvement of Escherichia coli production strains by modification of the phosphoenolpyruvate:sugar phosphotransferase system. Microb Cell Factories 2005, 4:14.

66. De Anda R, Lara AR, Hernández V, Hernández-Montalvo V, Gosset G, Bolívar F, Ramírez OT: Replacement of the glucose phosphotransferase transport system by galactose permease reduces acetate accumulation and improves process performance of Escherichia coli for recombinant protein production without impairment of growth rate. Metab Eng 2006, 8:28I-90.

67. Zastrow CR, Mattos MA, Hollatz C, Stambuk BU: Maltotriose metabolism by Saccharomyces cerevisiae. Biotechnol Lett 2000, 22:455-459.

68. Zastrow CR, Hollatz C, de Araujo PS, Stambuk BU: Maltotriose fermentation by Saccharomyces cerevisiae. J Ind Microbiol Biotechnol 200I, 27:34-38.

69. Malluta EF, Decker P, Stambuk BU: The Kluyver effect for trehalose in Saccharomyces cerevisiae. J Basic Microbiol 2000, 40:199-205

70. Jules M, Guillou V, Francois J, Parrou J: Two distinct pathways for trehalose assimilation in the yeast Saccharomyces cerevisiae. Appl Environ Microbiol 2004, 70:2771-2778.

7I. Jules M, Francois J, Parrou J: Autonomous oscillations in Saccharomyces cerevisiae during batch cultures on trehalose. FEBS J 2005, 272: I490-500.

72. Mouret JR, Jacobsen JN, Guillouet SE: Kinetic analysis of a trehalase-overexpressing strain grown on trehalose: a new tool for respire-fermentative transition studies in Saccharomyces cerevisiae. Lett Appl Microbiol 2006, 42:363-368.

73. Goffrini P, Ferrero I, Donnini C: Respiration-dependent utilization of sugars in yeasts: a determinant role for sugar transporters. J Bacteriol 2002, I 84:427-432.

74. Ausubel FM, Brent R, Kingston RE, Moore DD, Seidman JG, Smith JA, Struhl K: Short Protocols in Molecular Biology 3rd edition. John Wiley \& Sons: New York, N.Y; 1995.

75. Petracek ME, Longtine MS: PCR-based engineering of yeast genome. Methods in Enzymol 2002, 350:445-469.
76. Guerring SL, Connelly C, Hieter P: Positional mapping of genes by chromosome blotting and chromosome fragmentation. Methods Enzymol 1991, 194:57-77.

77. Rice JF, Sullivan TR, Helbert JR: A rapid method for the determination of yeast dry weight concentration. J Am Soc Brew Chem 1980, 38:142-145.
Publish with Biomed Central and every scientist can read your work free of charge

"BioMed Central will be the most significant development for disseminating the results of biomedical research in our lifetime. "

Sir Paul Nurse, Cancer Research UK

Your research papers will be:

- available free of charge to the entire biomedical community

- peer reviewed and published immediately upon acceptance

- cited in PubMed and archived on PubMed Central

- yours - you keep the copyright 